\title{
The effect of fundus resection on weight loss and ghrelin levels in rats
}

\author{
Okus $\mathrm{A}^{1}$, Sevinc $\mathrm{B}^{2}$, Karahan $\mathrm{O}^{3}$, Ay $\mathrm{S}^{4}$, Civcik $\mathrm{S}^{5}$ \\ Department of General Surgery, Mevlana University Medical School, Konya Turkey. \\ drbarissevinc@gmail.com
}

\begin{abstract}
BACKGROUND: Ghrelin is a 28-amino acid peptide that is isolated mainly from the oxyntic glands of the stomach, especially fundus. Ghrelin administration, either centrally or peripherally, increases food intake and body weight in both rodents and humans. This study evaluates the effects of fundus resection and sclerosing agent injection on ghrelin level and weight loss.

MATERIAL AND METHODS: Thirty rats were divided into three groups. In group 1, $\mathrm{NaCl}$ was injected into the submucosal space at the gastric fundus while in Group 2, a sclerosing agent was injected into the latter site. In group 3, gastric fundus was resected. Ghrelin levels and weight were recorded.

RESULTS: In group 1, rats continued gaining weight and ghrelin levels stayed stable. In group 2, rats' weight and ghrelin levels stayed stable and in group 3, while weight stayed stable, ghrelin levels decreased significantly. CONCLUSION: In rats, the resection of fundus stabilizes weight gain and decreases ghrelin levels. However, in sclerotherapy, although weight gain was stabilized, there was no decrease in ghrelin levels. In humans, the effect of fundus resection on weight gain can usher in a new era of investigation (Tab. 2, Ref. 16). Text in PDF www.elis.sk. KEY WORDS: fundus resection, sclerotherapy, ghrelin.
\end{abstract}

\section{Introduction}

Ghrelin is a 28-amino acid peptide that is isolated mainly from mainly the oxyntic glands of the stomach, especially fundus (1). This peptide hormone is a natural ligand of the growth hormone (GH) secretagogue receptor and stimulates GH release and food intake. Ghrelin has orexigenic effects and is associated with several body systems. Ghrelin administration, either centrally or peripherally, increases food intake and body weight in both rodents and humans (2). These effects of ghrelin are independent of GH stimulation and are mediated by modulating the expression of various hypothalamic peptides via an interaction with the hypothalamic neuromodulator pathways. Ghrelin stimulates the activity of neurons expressing NPY, AgRP, and orexin. The appetite stimulation by peripheral ghrelin is probably due to its action via the afferent vagal nerve. Also ghrelin is produced locally in the hypothalamus and it may directly affect various hypothalamic nuclei. This peptide hormone affects the regulation of energy balance $(3,4)$. The secretion of ghrelin by the stomach depends largely on the nutritional state. Ghrelin levels show a diurnal variation; pre-prandial

${ }^{1}$ Department of General Surgery, Mevlana University Medical School, Konya Turkey, ${ }^{2}$ Department of General Surgery, Sarikaya State Hospital, Yozgat, Turkey, ${ }^{3}$ Department of General Surgery, Necmettin Erbakan University, Meram Medical School, Konya, Turkey, ${ }^{4}$ Department of General Surgery, Malazgirt State Hospital, Mus, Turkey, and ${ }^{5}$ Department of Biochemistry, Konya Training and Research Hospital, Konya, Turkey

Address for correspondence: B. Sevinc, Sarikaya State Hospital, Sarikaya, Yozgat, Turkey.

Phone: +905054880511 increases and postprandial decreases. In addition, ghrelin levels seem to be influenced by age, gender, BMI, growth hormone, glucose and insulin $(4,5)$.

Reports showed that in rats and humans, weight is lost and ghrelin levels are decreased after sleeve gastrectomy $(6,7,8)$.

This study evaluates the effects of fundus resection and sclerotherapy on ghrelin level and weight loss.

\section{Material and method}

Ethical committee approval was obtained from Selçuk University Application and Research Center for Experimental Medicine Ethical Committee. Thirty Wistar albino rats of 250-350 gr of weight, 4-6 months of age were divided into three groups as 10 rats in each groups. Oral intake of the rats was stopped one day before the procedure. The operation was performed under general anesthesia by giving intraperitoneal ketamine hydrochloride (80 $\mathrm{mg} / \mathrm{kg}$ ) (Ketalar, Pfizer Ilac, Istanbul, Turkey) and xylazin (10 $\mathrm{mg} / \mathrm{kg}$ ) (Rompun, Bayer, Germany). The area was cleaned with povidion iodine after shaving the hair. In all rats, laparatomy was performed with an incision of $3 \mathrm{~cm}$ at the midline. Before the procedure $0.5 \mathrm{ml}$ of blood was obtained from all rats.

In group 1, after laparotomy, the stomach was opened on the anterior surface at the fundus-corpus junction. A volume of $1.5 \mathrm{ml}$ of $0.9 \% \mathrm{NaCl}$ solution was injected to submucosal space as to bloat the fundus. Then gastric wall was repaired by $4 / 0$ silk suture (Dogsan, Trabzon, Turkey) and abdominal wall was closed by $3 / 0$ silk suture.

In group 2 , the same procedure was performed. The only difference was that instead of $\mathrm{NaCl}$ solution, $1 \mathrm{cc}$ solution of $1 \%$ 
Tab. 1. Weekly weight gain according to index weight.

\begin{tabular}{|c|c|c|c|c|c|c|}
\hline & & 1st week & 2nd week & 3rd week & 4th week & 5th week \\
\hline \multirow{2}{*}{ Group 1} & Weight* & $233.14 \pm 27.9$ & $239.14 \pm 29.1$ & $248.43 \pm 27.8$ & $257.42 \pm 30.4$ & $267.56 \pm 25.6$ \\
\hline & $\mathrm{P} * *$ & & 0.004 & 0.001 & 0.001 & 0.001 \\
\hline \multirow{2}{*}{ Group 2} & Weight & $257,77 \pm 43.9$ & $262.62 \pm 43.6$ & $266.74 \pm 46.1$ & $265.77 \pm 43.5$ & $263.48 \pm 43.6$ \\
\hline & $\mathrm{P}^{* *}$ & & 0.011 & 0.003 & 0.026 & 0.244 \\
\hline \multirow{2}{*}{ Group 3} & weight & $315.4 \pm 43.5$ & $311.79 \pm 41.8$ & $314.81 \pm 42$ & $313.25 \pm 40$ & $306.27 \pm 38.5$ \\
\hline & $\mathrm{P}^{* *}$ & & 0.111 & 0.851 & 0.623 & 0.161 \\
\hline
\end{tabular}

* weight is given in grams \pm standard deviation, $* *$ One-way ANOVA

polydocanol (Aethoxysklerol 1 \%, Cem Farma Lap Ilac Medikal End Tic ve Paz Ltd Şti, Turkey) was used as a sclerosing agent.

In group 3, after laparotomy, gastric fundus was resected by LigaSure (Force Triad Energy Platform, Covidien, USA) LS1200 probe. The remaining gastric wall was repaired by $4 / 0$ silk suture and the abdominal wall was closed in the same way as in the other groups.

After the procedures, the rats were put into cages and they were given standard food. Rats were weighted once a week. At the 4th week, $0.5 \mathrm{ml}$ blood sample was obtained under general anesthesia and rats were decapitated.

Blood samples were centrifuged at 3,200 rpm for 10 minutes (Nüve-NF 1000 R). Serum samples were stored at -80 degrees Celsius. At the end of the study all ghrelin levels were measured by commercially available rat ghrelin kit (Ghrelin Rat Kit, Phoenix Pharmaceuticals Inc, USA). Results were given in pg/ml.

In statistical analysis IBM SPSS version 20 statistical package was used. In quantitative variables student $T$ test, one-way ANOVA and in subgroup analysis, Tukey's multiple comparison tests were used. Statistical significance was accepted at the level of 0.05 .

\section{Findings}

In group 1 (control group), at weekly weights, rats' mean weight was significantly higher than in the previous week $(\mathrm{p}<$ $0.05)$. Rats continuously gained weight every week. Moreover, ghrelin levels did not change at the 4th week $(p>0.05)$. Rats' weights and ghrelin levels are given in Tables 1 and 2, respectively.

In group 2 (sclerotherapy group), the rats stopped gaining weight at the second week and their weight stayed stable at the end of the 4 th week $(p>0.05)$. Likewise, their ghrelin levels stayed stable $(\mathrm{p}>0.05)$.

In group 3 (resection group), there was a small weight loss at every week. However, this loss was not statistically significant $(p>0.05)$. Although, rats' weight stayed stable during the study, their ghrelin levels decreased significantly at the end of the 4th week $(\mathrm{p}<0.05)$.

\section{Discussion}

As it has a positive relation to mortality, obesity is one of the most important healthcare problems in developed countries (9). Leptin, secreted from adipose tissue, has an anorexic effect on hypothalamus, whereas ghrelin has an orexigenic effect (4).
Tab. 2. Ghrelin levels.

\begin{tabular}{lccc}
\hline & Before the procedure & 4th week & $\mathrm{p}$ \\
\hline Group 1 & 0.8643 & 0.8884 & 0.343 \\
Group 2 & 0.8589 & 0.7346 & 0.392 \\
Group 3 & 0.8015 & 0.2456 & 0.008 \\
\hline
\end{tabular}

*Student T test, Ghrelin levels are given in $\mathrm{pg} / \mathrm{ml}$

Ghrelin is secreted as preproghrelin (117 aa) and transformed into 28 aa ghrelin. Its halftime is 60 minutes and it is transformed from active $\mathrm{N}$-octanoyl into inactive desacyl $\mathrm{N}$-octanoyl form by plasma esterase.

Several studies showed that ghrelin promotes growth hormone release, stimulates appetite and has several other effects on several systems. Briefly, ghrelin hormone is a main factor in the regulation of feeding behavior and energy homeostasis $(3,10)$.

Ghrelin secreted from several tissues like placenta, testis, kidney, brain and intestines. However, majority of ghrelin (90\%) is secreted from the gastric fundus (3). In our study, sclerotherapy caused a little and non-significant decrease in ghrelin levels. A significant ghrelin decrease could only be achieved by fundus resection.

In histopathological examination of sleeve gastrectomy materials, Gündogan et al reported that fundus and proximal corpus contains significantly more ghrelin immunopositive cells compared to distal corpus (11). Additionally, the number of Ghrelin immunopositive cells in the gastric mucosa in females was significantly higher compared to males.

Tsoli et al reported sleeve gastrectomy and biliopancreatic diversion procedures to be similar in terms of weight loss and recovery in types 2 diabetes. Although, there was no decrease in ghrelin levels in the diversion group, ghrelin levels decreased significantly in sleeve gastrectomy group (6). Moreover, other studies show a significant decrease in ghrelin levels in gastric resections including fundus (12). In patients with total gastrectomy, ghrelin levels found to be $50 \%$ lower than in healthy individuals (13).

Those reports show that to decrease ghrelin level, the fundus resection is a must. In our study, sclerotherapy has no significant effect, neither on weight gain nor on ghrelin level.

Wren et al evaluated food intake and weight gain on rats after administration of ghrelin (2). After chronic systemic or intracerebroventricular administration of ghrelin for 7 days, cumulative food intake was increased. Also ghrelin administration was associated with excess weight gain and adiposity. These findings are in keeping with the physiological role for circulating ghrelin in the regulation of food intake. As such, ghrelin would be an important 
new target for the development of treatments for obesity. Ghrelin administration induces dose-dependent contractions in the antrum and increases the motility in rodents and humans $(14,15)$.

Also the potential of the ghrelin system as a therapeutic target for obesity treatment is still under discussion. As it has been demonstrated that circulating ghrelin levels increase when obese humans lose weight, and because obese mice show an increase in sensitivity to ghrelin upon weight loss, the blockage of ghrelin could prevent weight regain after weight loss (15). In a recent study with rats, it was demonstrated that anti-ghrelin (Spiegelmer NOX-B11) blocks the ghrelin-induced increase in food intake after ghrelin injection (16). This biological agent suppresses ghrelininduced food intake and ghrelin-induced neuronal activation in the arcuate nucleus.

In rats, the resection of fundus stabilizes weight gain and decreases ghrelin levels. In sclerotherapy however, weight gain was stabilized despite the fact that ghrelin levels did not decrease. In humans, the effect of fundus resection on weight gain can usher in a new era of investigation.

\section{References}

1. Date Y, Kojima M, Hosoda H, Sawaguchi A, Mondal MS, Suganuma T, Matsukura S, Kangawa K, Nakazato M. Ghrelin, a novel growth hormone-releasing acylated peptide, is synthesized in a distinct endocrine cell type in the gastrointestinal tracts of rats and humans. Endocrinology 2000; 141: 4255-4261.

2. Wren AM, Small CJ, Abbott CR, Dhillo WS, Seal LJ, Cohen MA, Batterham RL, Taheri S, Stanley SA, Ghatei MA, Bloom SR. Ghrelin causes hyperphagia and obesity in rats. Diabetes 2001; 50: 2540-2547.

3. Bilgin HM. Ghrelin; Gündemdeki Hormon. Dicle Tip Dergisi 2006; 33: $268-272$.

4. Klok MD, Jakobsdottir S, Drent ML. The role of leptin and ghrelin in the regulation of food intake and body weight in humans: a review. Obes Rev 2007; 8: 21-34.

5. Ariyasu H, Takaya K, Tagami T, Ogawa Y, Hosoda K, Akamizu T, Suda M, Koh T, Natsui K, Toyooka S, Shirakami G, Usui T, Shimatsu A, Doi K, Hosoda H, Kojima M, Kangawa K, Nakao K. Stomach is a major source of circulating ghrelin, and feeding state determines plasma ghrelin-like immunoreactivity levels in humans. J Clin Endocrinol Metab 2001; 86: 4753-4758.
6. Tsoli M, Chronaiou A, Kehagias I, Kalfarentzos F, Alexandrides TK. Hormone changes and diabetes resolution after biliopancreatic diversion and laparoscopic sleeve gastrectomy: a comparative prospective study. Surg Obes Relat Dis 2013; Jan 13 [Epub ahead of print].

7. Hady HR, Dadan J, Golaszewski P, Safiejko K. Impact of laparoscopic sleeve gastrectomy on body mass index, ghrelin, insulin and lipid levels in 100 obese patients. Wideochir Inne Tech Malo Inwazyjne 2012; 7: 251-259.

8. Guimarães M, Nora M, Ferreira T, Andrade S, Ribeiro AM, Oliveira V, Carreira MC, Casanueva FF, Monteiro MP. Sleeve Gastrectomy and Gastric Plication in the Rat Result in Weight Loss with Different Endocrine Profiles. Obes Surg 2013; Mar 13 [Epub ahead of print].

9. Orzano AJ, Scott JG. Diagnosis and treatment of obesity in adults: an applied evidence-based review. J Am Board Fam Pract 2004; 17: 359-369.

10. Shiiya T, Nakazato M, Mizuta M, Date Y, Mondal MS, Tanaka M, Nozoe S, Hosoda H, Kangawa K, Matsukura S. Plasma ghrelin levels in lean and obese humans and the effect of glucose on ghrelin secretion. J Clin Endocrinol Metab 2002; 87: 240-244.

11. Gündoğan M, Çalli Demirkan N, Tekin K, Aybek H. Gastric histopathological findings and ghrelin expression in morbid obesity. Turk Patoloji Derg 2013; 29: 19-26.

12. Rodríguez A, Becerril S, Valentí V, Moncada R, Méndez-Giménez L, Ramírez B, Lancha A, Martín M, Burrell MA, Catalán V, GómezAmbrosi J, Frühbeck G. Short-term effects of sleeve gastrectomy and caloric restriction on blood pressure in diet-induced obese rats. Obes Surg 2012; 22: 1481-1490.

13. Popovic V, Miljic D, Pekic S, Pesko P, Djurovic M, Doknic M, Damjanovic S, Micic D, Cvijovic G, Glodic J, Dieguez C, Casanueva FF. Low plasma ghrelin level in gastrectomized patients is accompanied by enhanced sensitivity to the ghrelin-induced growth hormone release. J Clin Endocrinol Metab 2005; 90: 2187-2191.

14. Fujimiya M, Asakawa A, Ataka K, Kato I, Inui A. Different effects of ghrelin, des-acyl ghrelin and obestatin on gastroduodenal motility in conscious rats. World J Gastroenterol 2008; 14: 6318-6326.

15. Tack J, Depoortere I, Bisschops R, Delporte C, Coulie B, Meulemans A, Janssens J, Peeters T. Influence of ghrelin on interdigestive gastrointestinal motility in humans. Gut 2006; 55: 327-333.

16. Kobelt P, Helmling S, Stengel A, Wlotzka B, Andresen V, Klapp BF, Wiedenmann B, Klussmann S, Monnikes H. Antighrelin SPIEGELMER NOX-B11 inhibits neurostimulatory and orexigenic effects of peripheral ghrelin in rats. Gut 2006; 55: 788-792.

Received September 30, 2015. Accepted October 5, 2015. 